\title{
Numerical and Experimental Investigation on the Modified of Hot Mix Asphalt Concrete Containing Crumb Rubber and Waste Pet
}

\author{
Mahmoud AMERI, Hamid SHAKER, Baitollah BADARLOO, Faezeh JAFARI
}

\begin{abstract}
The main objective of this research is to investigate the rutting of modified mixtures with two additives of crumb rubber and polyethylene terephthalate (PET).Therefore, ITS method, resilient modulus and Dynamic creep were used to investigate asphalt behaviour with these two additives in this article. Modified blends include ten blends that are made by combining crumb rubber and polyethylene terephthalate in various percentages. The modifiers are combined in two percent $10 \%$ and $15 \%$ with $60 / 70$ penetration bitumen. Finally, with these mentioned tests, the results of the ten modified samples along with the non-modified one were compared. The results showed that the addition of polyethylene terephthalate increased the viscosity and reduced the density; therefore, addition of more polyethylene terephthalate in the modifier reduces the flow number and, on the other hand, addition of $15 \%$ modifier containing polyethylene terephthalate resilient module increases the flow number by about $66 \%$. Ultimately, neural network method was used to predict the result of dynamic creep test; indirect tensile strength and the capability of neural network method have been measured to estimate the laboratory result. According to the results, ANFIS can estimate the laboratory data correctly.
\end{abstract}

Keywords: asphalt mixtures; crumb rubber; dynamic creep; neural network method; polyethylene; resilient modulus

\section{INTRODUCTION}

Polymer implication for improving the properties of bitumen in a road pavement has been used more excessively. In this way, the road life span and consequently operation life have been significantly increased. To do this, polymer as the major bitumen modifier, is added to increase and improve its efficiency. [1]. Bituminous can be mentioned as one of the asphalt modification methods which is done by use of a wide range of modifiers [2]. The two main types of polymer additives, including elastomers (TPE) and plastomers, are increasingly used for bitumen modification purposes. Plastomers can be used to improve bitumen to increase rutting resistance at operating temperatures. Also, elastomers (such as styrene-butadiene-styrene-SBS) increase the bitumen adhesion resistance, fatigue resistance, and reduce the thermal rutting sensitivity. The composition of materials in bitumen is such that it allows the use of plastic waste made of polyethylene (PET) to improve some of the properties of bitumen [3]. To investigate the asphalt behavior, various experiments have been used in the research, and in each experiment, it is investigated based on its unique features [4-5], such as using different loading modes to investigate the characteristics of fracture mechanics, using the indirect tensile test to investigate the moisture sensitivity, and dynamic modulus test. Various researchers have investigated the properties of asphalt and additives, for example: the use of plastic bottle trash in SMA mixtures can increase rutting resistance and hardness of the mixture [6]. The addition of plastic bottle waste to hot asphalt mixtures increases the bitumen hardness and increases the viscosity of modified mixtures, which results in reduction of the asphalt samples density [7]. On the other hand, the use of other recycled materials, such as crumb rubber, can improve the resistance and properties of the bitumen viscosity and slightly increase the viscosity due to loss of some of the oils in the process of mixing crumb rubber and bitumen [8]. The researchers have reported some advantages of using crumb rubber in asphalt which such as improving the bitumen resistance to permanent deformation due to high viscosity, increasing penetration and improving resilience, increasing bitumen resistance to emerging surface cracks, reducing fatigue cracks and improving pavement durability [9]. Wulandari, P. S. et al. has used CR in hot mix asphalt mixture; the amount of crumb rubber in this research is 1 and 2\%. Wulandari, P. S. has used CR in hot mix asphalt mixture. In this research the amount of crumb rubber is 1 and $2 \%$. Wulandari, P. S. has tested marshal stability and volumetric properties. Using crumb rubber increases the strength and quantity of asphalt [10]. Kok et al. in 2011 replaced some portion of bitumen by CR and conducted dynamic creep test, indirect tensile strength test, fatigue test and rotational viscometer test and investigated the impact of CR on bitumen properties. The result shows that adding 50\% CR instead of bitumen, increases the stiffness modules by $50 \%$ [11]. Aiyapijati in 2017 studied crumb rubber in asphalt and its impact on resident modules. The result of this research shows that using additive improves elastic property, and consequently decreases crack on the road surface while load resistance decreases [12].

Neural network has been used by the researchers to estimate material properties in recent laboratory test. For example, Sodikov in 2005 predicted the cost of highway project by applying ANN method. Lack of preliminary information, database of road work, and some other problem can be compensated by using network model for classifying data [13]. Tapkin in 2010 used PP for enhancing the physical and mechanical properties of the asphaltic mixture. After laboratory test, ANN was used for obtaining the result of experimental test and this method can predict experimental data accurately [14]. Tian in 2015 used RBF neural network and MIV algorithm to obtain the factors affecting the asphalt pavement performance. The result of this study shows that the simulated results of RBF will be calculated faster and more accurately, however, the MIV is more feasible than simulated results for variable selection [15]. Tarefder in 2016 utilized neural network (ANN) to evaluate the influence of types and value of chemical ant stripping agents (ASAs) on the adhesion force of polymer 
[16]. The application of PET as an elastomer and its effect on asphalt behavior has been seen in previous studies. In addition, the use of the waste material in the design of hot-mix asphalt concrete can reduce environmental pollution and ultimately reduce the used bitumen [17]. It is also expected that using the material as a coat for the aggregate could improve the bitumen moisture behavior [18]. On the other hand, the application of CR as an elastomer has been seen in previous studies, and according to the research, CR has properties such as rigidity and elastic deformation under loading. Also, the production of the material as a waste material and environmental pollutant in various industries leads to environmental pollution, so that it usually takes years for the material to be eliminated in nature. However, previous research on the use of this material for asphalt has shown that it can be effective in improving the asphalt behavior [19]. The mixing of the two materials as an additive has not yet been observed in any research, while the study of the asphalt properties when using only one of the materials has been seen in previous studies. In this research, it is tried to study the behavior of asphalt by making a new material (a mixture of PET and CR) as an additive and to observe the effect of using the two materials on improving the asphalt behavior. It is expected that using the two additives will not only improve the asphalt behavior, but also help reduce the environmental pollutants by eliminating the two waste materials in nature. The main objective of this research is to study the characteristics of the rutting and the resilient modulus of modified asphalt mixtures by combining rubber waste bottles polyethylene terephthalate and crumb rubber. These two materials have been used together as they are PET (plastomer) and CR (elastomer). Consequently, indirect tensile strength, and dynamic creep were done to specify the optimum percentage of these two modifiers, then laboratory test estimation was done through this method and the efficiency of ANFIS was evaluated in predicting the result. Moreover, in the previous research, ANN was always used to predict experimental test, however, in this study, ANFIS as a new method was employed.

\section{MATERIAL}

In this research, pure bitumen with a penetration level of $60 / 70$ has been produced by Pasargad Company in Tehran. Material grading affects the main properties of an asphalt mixture including stiffness, durability, penetrability, efficiency, fragile stability, moisture susceptibility [20]. In this research, stone material which was extracted from Telo mine in Tehran was aggregated based on "ASTM D3515". Samples coming out of extruder set up were ground in order to have a similar condition. This process was applied for samples including $100 \% \mathrm{CR}$ and $100 \%$ PET to create similar condition which other samples had. Other volumetric and mechanical properties of hot mixed asphalt in the optimum bitumen percentage included sample real density, percentage of void ratio, flow and stability which are respectively $2420,2.9,4$ and 8.3 . Fig. 1 shows the particle size distribution for stone mastic asphalt mixture.

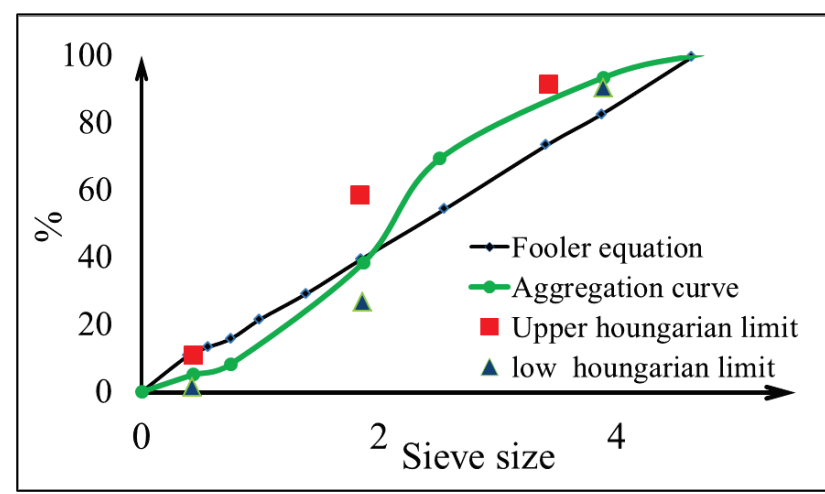

Figure 1 Particle size distribution for stone mastic asphalt mixture

The percentage of modifier is $10 \%$ and $15 \%$ of bitumen. The amount of these two modifiers usage depends on the expected performance in asphalt mixture which was $7 \%$ to $15 \%$ of bitumen weight in the previous research. The samples are made by gyratory set up. On the whole for controlling the sample and sample container modifiers, 132 samples were made. For each group of samples three samples were made and ultimately the average was extracted.

\subsection{Preparation of Samples}

In this research, polyethylene terephthalate (PET) and crumb rubber (CR) were used to improve bitumen. Crumb rubber has been produced in Kavir Company, based on tube and strip. Polyethylene terephthalate with BG 1021 trade name is semi-crystalline and manufactured in Malaysia. Mixing method of these two additives has been shown in Tab. 1. To mix two additives together and ensure the mixing of two materials, the twin Plastics extrusion is used. Plastics extrusion is a highvolume manufacturing process in which raw plastic is melted and formed into a continuous profile. The first to develop modern extruder was Thomas Hancock. In 1820, he created a rubber designed, and ultimately Edwin Chaffee in 1836 built two-roller machines for mixing additives into rubber [21]. The input parameters of this machine include the temperature of three barrels and the rotation rate for mixing the two materials. According to the usual procedure and the recommendations in the references, the temperature of the first, second and third barrels is set at $270{ }^{\circ} \mathrm{C}, 280{ }^{\circ} \mathrm{C}$ and $270{ }^{\circ} \mathrm{C}$, respectively. It also uses a rotation rate of $200 \mathrm{rpm}$. The output of this machine is PET and CR which are eventually powdered and mixed with bitumen using the high shear machine. High shear processing equipment is a machine to mix ingredients that do not mix naturally such as resin and resin (blend), resin and a filler (composite), etc. NHSS, our high shear machine, can mix these ingredients in micron $(1 / 1000 \mathrm{~mm})$ or even in nano $(1 / 1000 \mu \mathrm{m})$ dimensions. The input parameters for the high shear machine include temperature, time and rotation rate, and the materials are powdered from $170{ }^{\circ} \mathrm{C}$ for 45 minutes at about $5000 \mathrm{rpm}$ and mixed with bitumen. Subsequently, the modified bitumen is mixed with aggregates at 140 $150{ }^{\circ} \mathrm{C}$ and the samples are compacted using the gyratory compactor. The compacted samples are then tested on schedule according to the related standard to the test in various experiments. In the present study, $7 \%$ void was 
used for the compaction of indirect tension samples, and the control of number of rotation was used for other samples [22-23]. Finally, ten types of modified bitumen, along with a kind of non-modified bitumen, were prepared. A total of 18 samples were prepared by Marshall Method to determine the optimum bitumen for the non-modified sample, and the optimum bitumen percent of non-modified sample was determined to be 5.4. Samples containing modifiers were made with the same percentage of bitumen as the non-modified sample using a gyratory compactor. Fig. 2 shows the preparation of samples.

Table 1 The percentage of combining two additives

\begin{tabular}{|c|c|c|c|c|c|c|}
\hline $\begin{array}{c}\text { PET / } \\
\%\end{array}$ & CR / \% & Additive / \% & \multicolumn{2}{|c|}{ Samples } & Row \\
\hline 0 & 100 & 15 & 10 & $15 \mathrm{C} 100 \mathrm{P} 0$ & $10 \mathrm{C} 100 \mathrm{P} 0$ & 2,1 \\
\hline 25 & 75 & 15 & 10 & $15 \mathrm{C} 75 \mathrm{P} 25$ & $10 \mathrm{C} 75 \mathrm{P} 25$ & 4,3 \\
\hline 50 & 75 & 15 & 10 & $15 \mathrm{C} 50 \mathrm{P} 50$ & $10 \mathrm{C} 50 \mathrm{P} 50$ & 6,5 \\
\hline 75 & 25 & 15 & 10 & $15 \mathrm{C} 25 \mathrm{P} 75$ & $10 \mathrm{C} 25 \mathrm{P} 75$ & 8,7 \\
\hline 100 & 0 & 15 & 10 & $15 \mathrm{C} 0 \mathrm{P} 100$ & $10 \mathrm{C} 0 \mathrm{P} 100$ & 10,9 \\
\hline
\end{tabular}

a)

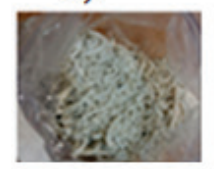

c)

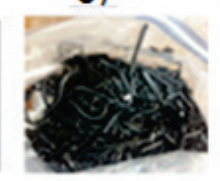

d)

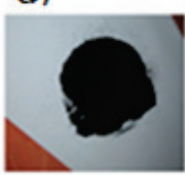

Figure 2 a) combination of $0.75 \mathrm{CR}$ and $25 \%$ PET b) combination of 0.75 PET and $25 \%$ CR c) combination of $100 \mathrm{CR} \%$ and $25 \%$ PET d) combination of 100 $\%$ PET and $25 \%$ CR.

\subsection{Experiments}

\subsubsection{Dynamic Creep}

The permanent deformation known as rutting is one of the most common damages in the asphalt pavement in warmer areas. Rutting reduces the service life. One of the methods for measuring the permanent deformation properties of asphalt mixtures is to apply several thousand loads repeatedly by a cyclic load test and recording permanent displacements as a function of a loading cycle. To achieve this goal, in this research, a dynamic creep test has been performed with UTM5 with a stress level of 450 $\mathrm{kPa}$ and a temperature of $50{ }^{\circ} \mathrm{C}$. Sample loading is continued until 0.01 strains [24]. For this purpose a square shaped load is applied for $0.1 \mathrm{~s}$ with 0.95 unloading time during the last on asphalt samples. The diameters of theses samples were 100 to $150 \mathrm{~mm}$ and the height of about $60 \mathrm{~mm}$. for the mixture with maximum size of aggregate $(37.5 \mathrm{~mm})$ [24-25]. Based on the Witzak theory, the number of loading until the beginning of the third region is known as a flow number, and the flow number is used as one of the best indices of rutting of asphalt mixture in most researches.

\subsubsection{Resilient Modulus}

Resilient modulus is a dynamic test response defined as the repetitive axial deviation stress ratio to reversible axial strain. Resilient modulus is used to evaluate the relative quality of the asphalt mixture as input data for pavement design, evaluation, or pavement analysis. This test was conducted based on the ASTM D4123 standard [26, 27], using the UTM5 device at $25{ }^{\circ} \mathrm{C}$ and the semisynthetic load. Eventually, the average of 5 final resilient modulus produced by the device as the output was reported as a resilient modulus of the mixtures.

\subsubsection{Indirect Tensile Strength (ITS) and Tensile Strength Ratio (TSR)}

ITS is one of the most important properties of pavement in loading in low temperature. ITS test can simulate loading mechanism in real condition. Also this test is used for determining damage to the pavement in low temperature (ASTMD6913) [26]. This test was conducted on wet and dry samples for obtaining the tensile strength ratio (TSR) of HMA according to ASHTO T 283 standard. One group of sample was totally dry because it was placed in the plastic bag and kept in isolated condition. While the wet group sample, according to the AASHTO T 283, were submerged under water and then exposed to the vacuum for 5 minutes under $137.9 \mathrm{kPa}$ loading for 5 minutes and kept at $-18{ }^{\circ} \mathrm{C}$ minimum for 16 hours. Samples were placed in the water with $60^{\circ} \mathrm{C}$ temperature and then soaked in the water bath with environmental temperature $\left(25^{\circ} \mathrm{C}\right)$ for one hour. Then this test was done in two conditions. Universal Testing Machine (UTM) was employed to calculate ITS values according to the proposed Eq. (1) [28]. Totally 66 samples were prepared for this test that 33 samples were tested in the wet conditions and other in dry situation. TSR index is obtained by dividing the average of three wet samples 'strength to the average of three dry samples' strength. This index is acceptable when it is roughly above $80 \%$ according to the previous research.

\subsubsection{ANFIS Part}

Adaptive neuro-fuzzy inference system is a kind of neural network system based on Takagi-Sugeno fuzzy inference system. Using this method was developed in 1990. This method benefits from the properties of both neural networks (ANN) and fuzzy logic principles. In this paper, this method is used to predict asphalt. For this aim, all data obtained through laboratory test were entered to MATLAB software as the output variable. The previous research that employed this method assumed the output and input variable as constant, however, in this research, the input variable was generated randomly by the mean and variance value was which obtained from laboratory test. In this research, the input value includes additive percentage to bitumen combination, percentage of crumb rubber in total additive and percentage of polyethylene terephthalate in total additive. The value of flow number, resilient modulus and tensile strength in wet and dry condition is assumed as output variable. The variance for input value has been assumed $0.1 *$ mean value with normal distribution. The variance for resilient modulus is 0.01 which has been driven from test data and the mean value is shown in the graph $1-3$. The output value is assumed as normal probabilistic function while mean value and variance are obtained from laboratory test, the maximum and minimum of each sample driven from laboratory test too. Using MATLAB software regenerated one datum between this maximum and minimum value. The number of data extracted from 
ANFIS GUI is 132 for resilient modulus and Flow number and 264 for tensile strength. This group of data is divided into 3 subsets as train, test and validation group. Ultimately, the probabilistic surface for input and the output variable was obtained via MATLAB software. This surface shows how additives can change output value and the effect of each variable on the output was tested.

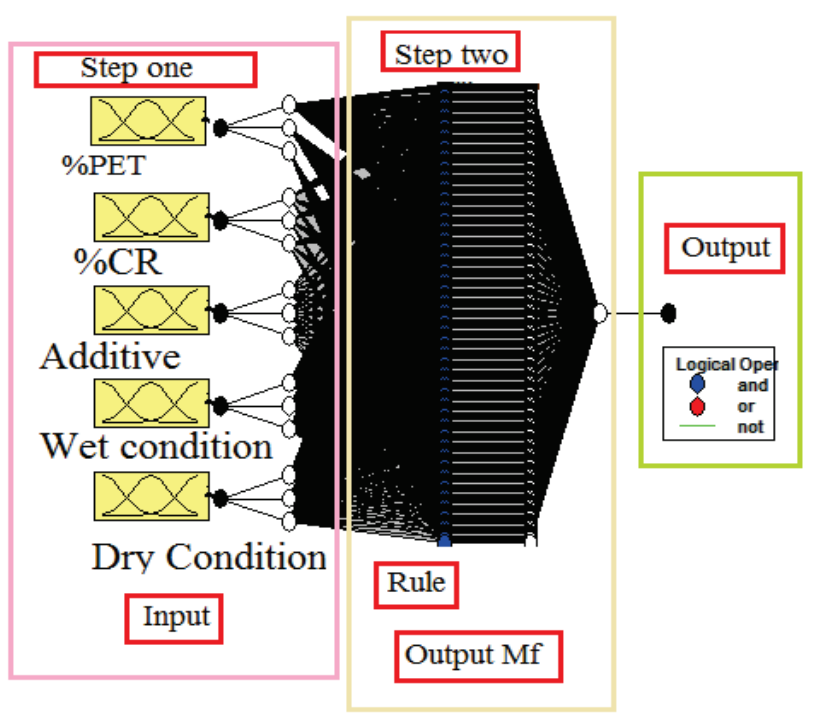

Figure 2 Fuzzy structure for tensile strength

In Fig. 2, all variables of the tensile strength test results entered the ANFIS environment as the inputs and were fuzzified using the WA and WS defuzzification rule. Eventually, they were prepared for building a neural network as a first-order polynomial output from the input variables to present the results of the defuzzification rule. In the second step, the network structure was constructed on the results (rule definition). Finally, the software estimated the results using the neural network technique (Step 3).

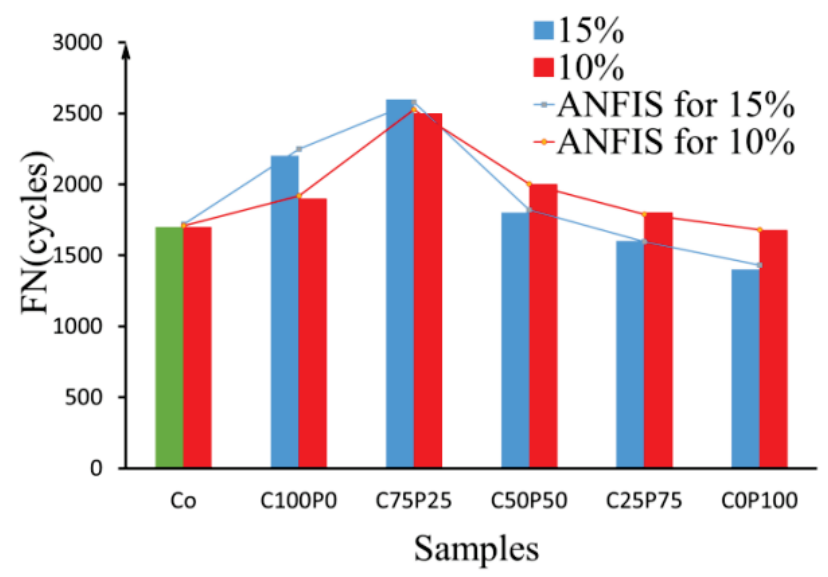

Figure 3 Flow number of samples

\section{RESULTS AND ANALYSIS}

\subsection{Dynamic Creep}

Fig. 3 shows the flow number for a modified sample with $10 \%$ and $15 \%$ modification. According to the data shown in this diagram, the flow number increased with the addition of modifiers to the sample. Also, by increasing the percentage of polyethylene terephthalate in the modifier from $0 \%$ to $25 \%$, flow number increases, but increasing this percentage from $25 \%$ to $50 \%, 50 \%$ to $75 \%$ and $75 \%$ to $100 \%$, the flow number reduces, and ultimately this decrease in the sample containing just polyethylene modifier is in a way that its flow number becomes even less than the non-modified sample flow number. The overall trend in these samples is similar to those containing $10 \%$, but the increments and decrements are different. With addition of just $15 \%$ crumb rubber additive, the flow number increases more compared to the samples with just $10 \%$ crumb rubber. Also, the amount of reduction is also more rapid than that of $10 \%$ modifier samples so that the flow number in the sample containing just $15 \%$ PET is much less than the non-modified sample and also the sample containing $75 \%$ PET and $25 \% \mathrm{CR}$ has a lower flow number than the non-modified. This process can have several reasons. First, samples containing crumb rubber, as noted in the review section, are largely lost due to mixing at high shear rates with bitumen which, in turn, can lead to a slight increase in viscosity of bitumen. In the process of mixing bitumen with stone materials, bitumen plays a role of lubrication among aggregates and causes better rotation and displacement of aggregates, which improves the properties of the aggregate interlock. By increasing the viscosity of bitumen, the effect of bitumen lubrication decreases, and the aggregate interlock is reduced, which reduces the resistance of the mixture against the repeated loads that occur. In this study, by increasing polyethylene in modifier, viscosity of the bitumen increases and this increase in viscosity, as in the recent researches, can reduce the density of the mixture and consequently, increase free space. On the other hand, this increase in viscosity increases the resistance of the mixture against the applied cycles, but this increase in resistance can somewhat resist the loads applied to the sample and with increasing number of loading cycles, the persistent deformations in the sample increase and the mixture itself shows more thermoplastic behaviour. This matter reduces the resistance of samples made with high percentages of polyethylene against rutting damage. In addition, by increasing the modifier percentage from 10 to $15 \%$, the amount of changes in viscosity increases. In sum, adding PET and $\mathrm{CR}$ increases the flow number. Similar to other researches, in this research flow numbers were increased by adding PET in the previous research. According to this research, using $\mathrm{CR}$ as additive has a positive impact on the flow numbers. The result of this test shows that employing CR and PET at the same time leads to enhancing the flow number. Another innovation of this study is adding more than $10 \%$ PET and the result showed that using more than $10 \%$ PET has negatively influenced the flow numbers. Adding 20\% CR prevents excessive decrease of the flow number. The sample containing $75 \% \mathrm{CR}$ and $25 \%$ PET has the best flow number in comparison with others. After that, adding 50\% CR, 50\% PET lead to the maximum flow number. According to Kök [11] using CR can increase the flow number and adding PET and CR has not been tested before; therefore, this study shows that adding these two modifiers can increase flow number. The value of flow number as the output layer is predicted through the neural network where the amount of $R^{2}$ is obtained for each network. The network results are summarized in Fig. 3 which shows high accuracy above $95 \%$ when $10 \%$ to $15 \%$ of the bitumen is formed. As can be seen, the neural network 
and experimental results are matched appropriately. The model defined in neural network and the predicted outputs were compared with the experimental results for flow number and presented in Fig. 3. The value of $R^{2}$ for all data is $98 \%$ and the neural network is very close to experimental result.

\subsection{Resilient Modulus}

The results of the resilient modulus of modified mixtures and the non-modified are shown in Fig. 4. According to this figure, with the addition of the CR, the resilient modulus increases slightly, but by increasing polyethylene in the modifier, increase in the resilient modulus is higher than the increase in the non-modified sample. Also, as shown in Fig. 4, increasing the modifier percentage from $10 \%$ to $15 \%$, the amount of resilient modulus increases. The results of this study can be justified in the light of the recently mentioned research that the hardening of the bitumen due to the presence of this type of polyethylene in the mixture as expected would increase the viscosity of the bitumen and, consequently, increase the stiffness of the mixtures that has been made. The sample containing $100 \%$ of the CR has a lower amount of increase compared to the rest of the percentages of these two additives and that is due to the high shear rate mixing process, as mentioned in the first section. The model defined in neural network and the predicted outputs were compared to the experimental results for resilient modulus, and are presented in Fig. 4. The value of $R^{2}$ for all data is $98 \%$, the result of the neural network is very close to experimental result.

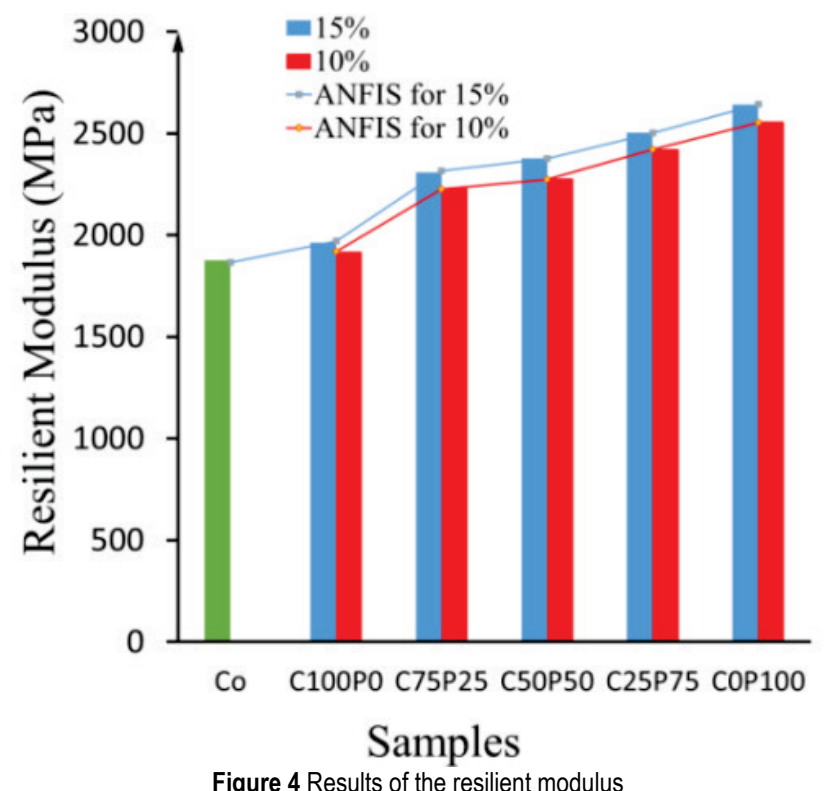

\subsection{Indirect Tensile Strength (ITS) and Tensile Strength Ratio (TSR) value}

Fig. 5 depicts the ITS value for different samples. According to the data shown in this diagram, the ITS increased with the addition of CR and PET to the sample. Also, by rising the percentage of polyethylene terephthalate in the modifier from $0 \%$ to $50 \%$, ITS rises in the dry condition; however, rising this percentage from $75 \%$ to $100 \%$, reduces the ITS value for dry condition, and ultimately it decreases in the sample containing just polyethylene modifier in a way that its ITS becomes even less than the sample having $50 \% \mathrm{CR}$ and $50 \%$ PET as modifier. In contrast, the ITS value decreases with the addition of PET instead of CR to the sample in the wet condition. Also, by rising the percentage of $\mathrm{CR}$ in the modifier from $0 \%$ to $50 \%$, ITS increases in the wet condition, while rising this percentage from $75 \%$ to $100 \%$ or addition of PET to the samples, reduces ITS for wet condition. The model built in neural network and the predicted outputs were compared to the experimental results for ITS, and the results are shown in Fig. 5. The overall value for $R^{2}$ is $94 \%$ and $95 \%$ for samples with dry and wet condition, respectively and the result of the neural network is very close to experimental result.
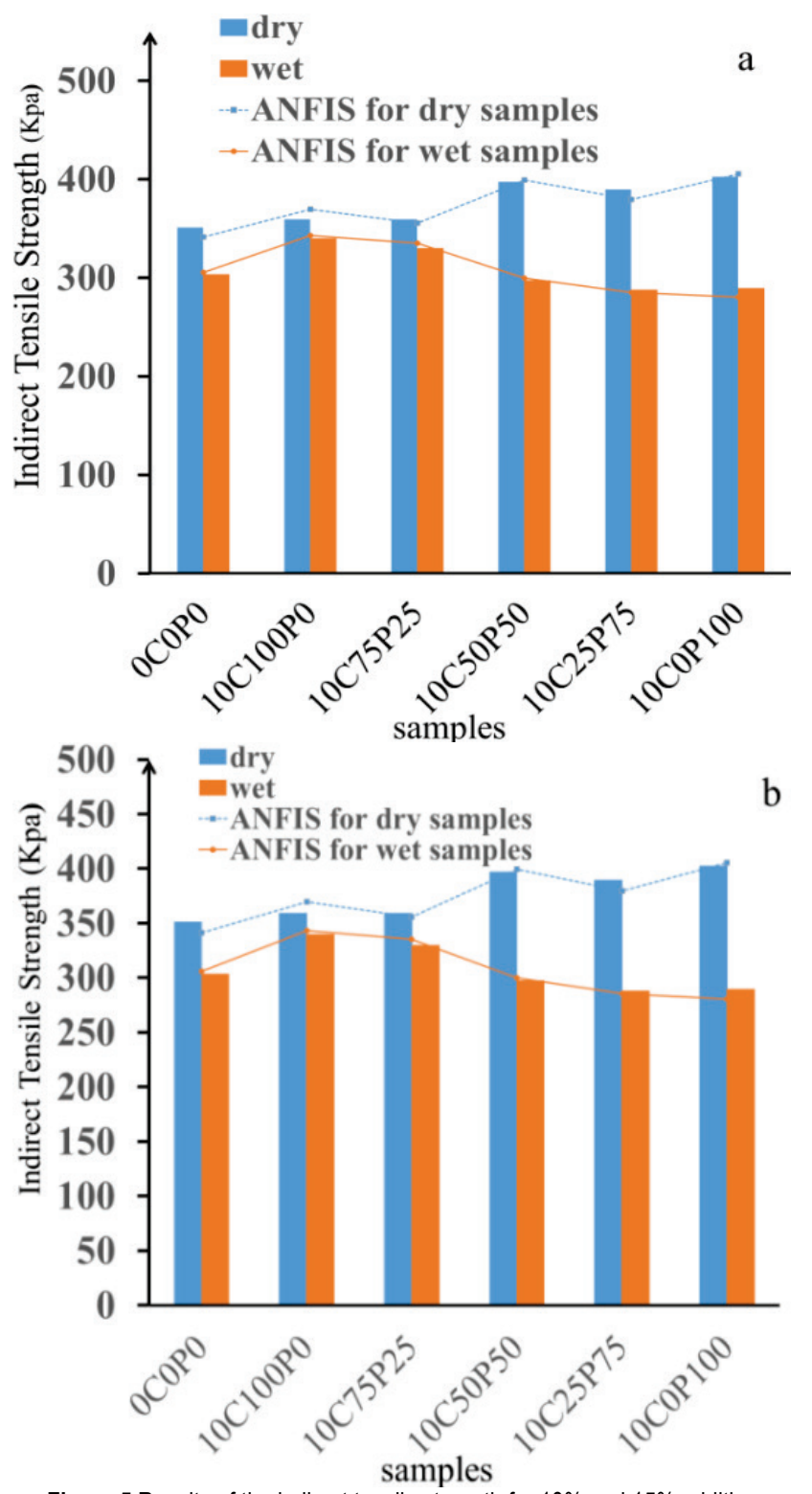

Figure 5 Results of the indirect tensile strength for $10 \%$ and $15 \%$ additive modified samples

Fig. 6 shows that TSR and the maximum value of this index depend on the specimen with $100 \%$ CR which shows these samples are less sensible to moisture. TSR decreases with increasing PET so that it reaches to less than $75 \%$ for specimen with $75 \%$ PET. It is novelty to mention that using $75 \% \mathrm{CR}$ increases TSR value when 
the amount of the modifier is 10 to 15 percent of the bitumen. Therefore, using these two additives increases TSR value, when the value of modifier (PET) is 5\% of bitumen weight according to Moghaddam et al. [29]. In the present research, the maximum TSR belongs to specimens with $75 \% \mathrm{CR}$ and $25 \%$ PET that increase TSR value and also ITS in wet and dry condition in comparison with other samples ( $75 \%$ PET or $100 \%$ PET). In other researches such as research conducted by Ahmadinia et al. [6], the maximum value for TSR depends on sample with 4\% PET. Using $0.75 \mathrm{CR}$ and 0.25 PET increases TSR number in this research and TSR reaches $92 \%$ that has a significant rise in comparison with the other research. In addition, using only $10 \%$ or $15 \%$ PET decreases TSR value.

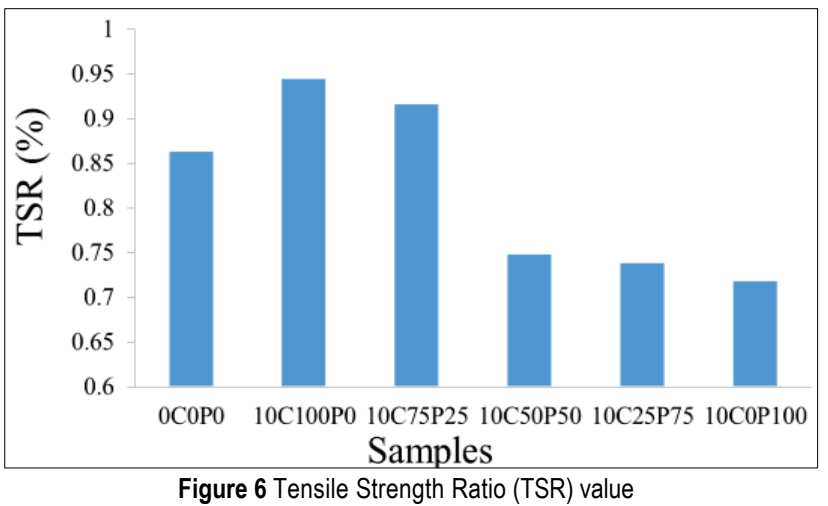

\subsection{ANFIS Result}

The efficiency and workability of ANFIS was measured based on two parameters $\left(R^{2}\right.$ and $\left.M S E\right)$ according to the previous research [30-32]. Neural network has the best workability when the value of $R^{2}$ is near to 1 and the RMSE value is close to zero. The validation of ANFIS model has been rated according to these two parameters. Tab. 2 shows these values for these models. ANFIS model can predict experimental results correctly as the amount of $R^{2}$ is nearly 1 and $R M S E$ is near 0 . Also, FIS models, which have been produced in this research, have capability of predicting output value close to real data; Fig. 3 to Fig. 6 show this fact.
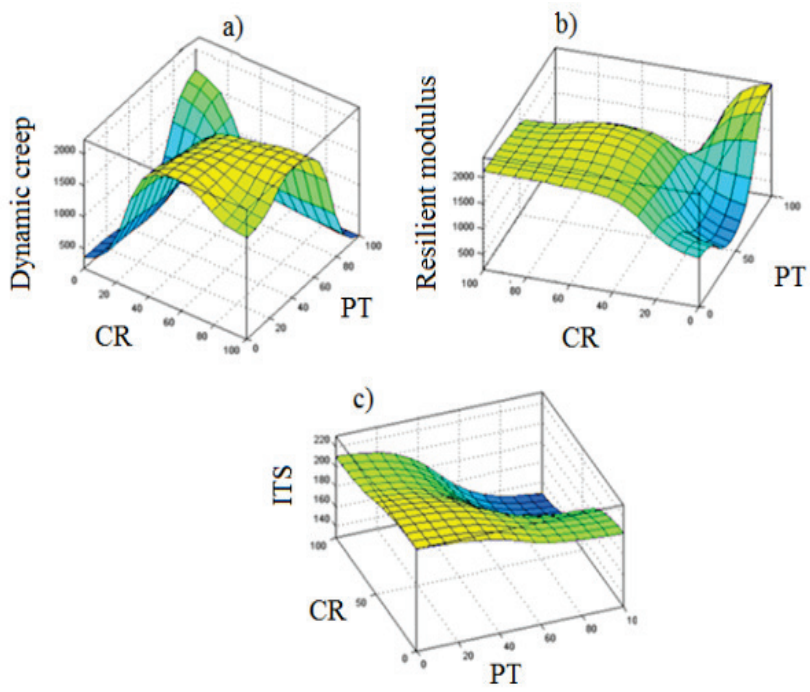

Figure 7 ANFIS results table
Fig. 7 shows the relationship between two input variables (PET and CR) and the output layers (flow number, tensile strength and dynamic creep). Fig. 7a shows the dynamic creep variation related to the CR and PET. This figure shows that the maximum variation of dynamic creep is related to $50 \% \mathrm{CR}$ and $50 \%$ PET and the surface variation decreases by reducing the value of $\mathrm{CR}$ and PET. The surface variation is more visible when the CR value is $100 \%$ or PET is $100 \%$. Fig. $7 \mathrm{~b}$ depicts the resilient modulus surface for the $\mathrm{CR}$ and $\mathrm{PET}$ and resilient modulus as a dependent variable. This figure displays that the maximum value belongs to $75 \% \mathrm{CR}$ and $25 \%$ PET and the surface variation reduces when the value of CR decreases. Fig. 7c shows the variation of ITS surface for the CR and PET and ITS as dependent variable. This figure displays that the maximum value belongs to $50 \% \mathrm{CR}$ and $50 \%$ PET and the surface variation reduces when the value of $\mathrm{CR}$ and $\mathrm{PET}$ increases.

Table 2 ANFIS result for indirect tensile test, resilient modulus and dynamic

\begin{tabular}{|c|c|c|c|c|c|c|}
\hline \multirow{2}{*}{ Output Layer } & \multicolumn{2}{|c|}{ Training set } & \multicolumn{2}{c|}{ Testing set } & \multicolumn{2}{c|}{ Validation set } \\
\cline { 2 - 7 } & $R^{2}$ & $R M S E$ & $R^{2}$ & $R M S E$ & $R^{2}$ & $R M S E$ \\
\hline ITS & 0.999 & 0.002 & 0.97 & 0.00025 & 0.9541 & 0.0035 \\
\hline $\begin{array}{c}\text { Dynamic } \\
\text { creep }\end{array}$ & 1 & 0.0036 & 0.79 & 0.00056 & 0.9928 & 0.0026 \\
\hline $\begin{array}{c}\text { resilient } \\
\text { modulus }\end{array}$ & 0.996 & 0.0025 & 0.97 & 0.0026 & 0.7861 & 0.0024 \\
\hline
\end{tabular}

\section{CONCLUSION}

This study was conducted to investigate the characteristics of the rutting and the resilient modulus of asphalt mixtures containing crumb rubber (CR) and polyethylene terephthalate (PET) modifiers in different percentages. The following results are obtained from this study:

- From the test results of the resilient modulus, using additives of both $10 \%$ and $15 \%$, increases the resilient modulus and this increase in the resilient modulus with the replacement of PET, instead of the CR, has an upward trend so that the ratio of the resilient modulus of the sample containing $15 \%$ of the PET additive is only $40 \%$ for the non-modified sample.

- Increasing the modifier from $10 \%$ to $15 \%$ also has a positive result and by increasing the amount of the modifiers a better result is obtained. The addition of PET, as it was seen in the previous research, increased the viscosity of bitumen and reduced interlock aggregates, which ultimately reduces the density of the mixture.

- $\quad$ CR the same as PET increases viscosity, but its rate is much lower than PET; therefore, the addition of PET causes more significant changes.

- Regarding environmental issues and priority of reducing rutting of modifiers with $75 \% \mathrm{CR}$ and $25 \% \mathrm{PET}$, this Mixture has better condition compared to other modified mixtures of this study.

- The result of moisture susceptibility shows that samples with $75 \% \mathrm{CR}$ and $15 \%$ PET had the optimum moisture susceptibility so that TSR has the maximum value for the samples.

- In samples in which only CR was replaced by $15 \%$ bitumen, scour is less compared to the situation in which 
the modifier forms $10 \%$ of bitumen weight, while this procedure is so different for other samples such as specimens with 50\% CR and 50\% PET.

\section{REFERENCES}

[1] Cuciniello, G., Leandri, P., Filippi, S., Presti, D. L., Losa, M., \& Airey, G. (2018). Effect of ageing on the morphology and creep and recovery of polymer-modified bitumens. Materials and Structures, 51(5), 136. https://doi.org/10.1617/s11527-018-1263-3

[2] Lu, X. \& Isacsson, U. (2000). Modification of road bitumens with thermoplastic polymers. Polym. Test, 20, 77-86. https://doi.org/10.1016/S0142-9418(00)00004-0

[3] Naskar, M., Chaki, T. K., \& Reddy, K. S. (2010). Effect of waste plastic as modifier on thermal stability and degradation kinetics of bitumen/waste plastics blend. Thermochim. Acta, 509, 128-134. https://doi.org/10.1016/j.tca.2010.06.013

[4] Mubaraki, M. \& Sallam, H. E. M. (2018). Reliability study on fracture and fatigue behavior of pavement materials using SCB specimen. International Journal of Pavement Engineering, 1-13. https://doi.org/10.1080/10298436.2018.1555332

[5] Mubaraki, M., Osman, S. A., \& Sallam, H. E. M. (2019). Effect of RAP content on flexural behavior and fracture toughness of flexible pavement. Latin American Journal of Solids and Structures, 16(3). https://doi.org/10.1590/1679-78255516

[6] Ahmadinia, E., Zargar, M., Karim, M. R., Abdelaziz, M., \& Ahmadinia, E. (2012). Performance evaluation of utilization of waste polyethylene terephthalate (PET) in stone mastic asphalt. Construction and Building Materials, 36, 984-989. https://doi.org/10.1016/j.conbuildmat.2012.06.015

[7] Ameri, M. \& Nasr, D. (2016). Properties of asphalt modified with devulcanized polyethylene terephthalate. Pet. Sci. Technol., 34, 1424-1430. https://doi.org/10.1080/10916466.2016.1202968

[8] Adhikari, B., De, D., \& Maiti, S. (2000). Reclamation and recycling of waste rubber. Progress in Polymer Science, 25, 909-948 . https://doi.org/10.1016/S0079-6700(00)00020-4

[9] Liu, S., Cao, W., Fang, J., \& Shang, S. (2009). Variance analysis and performance evaluation of different crumb rubber modified (CRM) asphalt. Construct. Build. Mater., 23, 2701-2708. https://doi.org/10.1016/j.conbuildmat.2008.12.009

[10] Wulandari, P. S. \& Tjandra, D. (2017). Use of crumb rubber as an additive in asphalt concrete mixture (Doctoral dissertation, Petra Christian University). https://doi.org/10.1016/j.proeng.2017.01.451

[11] Kök, B. V. \& Çolak, H. (2011). Laboratory comparison of the crumb-rubber and SBS modified bitumen and hot mix asphalt. Construction and Building Materials, 25(8), 32043212. https://doi.org/10.1016/j.conbuildmat.2011.03.005

[12] Ariyapijati, R. H., Hadiwardoyo, S. P., \& Sumabrata, R. J. (2017). Contributions crumb rubber in hot mix asphalt to the resilient modulus. In AIP Conference Proceedings, 1855(1), 030005. https://doi.org/10.1063/1.4985475

[13] Sodikov, J. (2005). Cost estimation of highway projects in developing countries: artificial neural network approach. Journal of the Eastern Asia Society for Transportation Studies, 6, 1036-1047. https://doi.org/10.11175/easts.6.1036

[14] Tapkın, S., Çevik, A., \& Uşar, Ü. (2010). Prediction of Marshall test results for polypropylene modified dense bituminous mixtures using neural networks. Expert Systems with Applications, 37(6), 4660-4670. https://doi.org/10.1016/j.eswa.2009.12.042

[15] Tian, P., Zhan, G. F., \& Nai, L. (2015). A Variable Selection for Asphalt Pavement Performance Based on RBF Neural
Network. In Applied Mechanics and Materials, 744, 12221225.

https://doi.org/10.4028/www.scientific.net/AMM.744-746.1222

[16] Tarefder, R. A., Ahsan, S., \& Arifuzzaman, M. (2016). Using a Neural Network Model to Assess the Effect of Antistripping Agents on the Performance of MoistureConditioned Asphalt. Journal of Materials in Civil Engineering, 29(4), 04016250. https://doi.org/10.1061/(ASCE)MT.1943-5533.0001777

[17] Sitinamaluwa, H. S. \& Mampearachchi, W. K. (2014). Development of a polymer-modified bitumen specification based on empirical tests-case study for Sri Lanka. Road Materials and Pavement Design, 15(3), 712-720. https://doi.org/10.1080/14680629.2014.909873

[18] Ahmad, A. F., Razali, A. R., Razelan, I. S. M., Jalil, S. S. A., Noh, M. S. M., \& Idris, A. A. (2017). Utilization of polyethylene terephthalate (PET) in bituminous mixture for improved performance of roads. In IOP Conference Series: Materials Science and Engineering, 203(1), 012005. https://doi.org/10.1088/1757-899X/203/1/012005

[19] Nguyen, H. T. \& Tran, T. N. (2018). Effects of crumb rubber content and curing time on the properties of asphalt concrete and stone mastic asphalt using dry process. International Journal of Pavement Research and Technology, 11(3), 236244. https://doi.org/10.1016/j.jprt.2017.09.014

[20] Asi, I. M. (2006). Laboratory comparison study for the use of stone matrix asphalt in hot weather climates. Construction and Building Materials, 20(10), 982-989. https://doi.org/10.1016/j.conbuildmat.2005.06.011

[21] Tadmor, Z. and Gogos, C. G. (2006). Principles of Polymer Processing. $2^{\text {nd }}$ Ed., John Wiley and Sons. ISBN 978-0-47138770-1

[22] Ishigami, A., Kodama, Y., Wagatsuma, T., \& Ito, H. (2017). Evaluation of Structures and Morphologies of Recycled PC/PET Blends Fabricated by High-Shear Kneading Processing. International Polymer Processing, 32(5), 568573. https://doi.org/10.3139/217.3423

[23] Peinado, V., Castell, P., García, L., \& Fernández, Á. (2015). Effect of extrusion on the mechanical and rheological properties of a reinforced poly (lactic acid): reprocessing and recycling of biobased materials. Materials, 8(10), 71067117. https://doi.org/10.3390/ma8105360

[24] Al-Qadi, I. L., Yoo, P. J., Elseifi, M. A., \& Nelson, S. (2009). Creep behavior of hot-mix asphalt due to heavy vehicular tire loading. Journal of engineering mechanics, 135(11), 126512. https://doi.org/10.1061/(ASCE)0733-9399(2009)135:11(1265)

[25] ASTM, D. (2004). 3515, Standard Specification for HotMixed, Hot-Laid Bituminous Paving Mixtures. Annual Book of Standards, 4

[26] ASTM D6913, Standard Practice for Preparation of Asphalt Mixture Specimens Using Marshall Apparatus

[27] ASTM D4123-82(1995), Standard Test Method for Indirect Tension Test for Resilient Modulus of Bituminous Mixtures

[28] Lavin, P. (2014). Asphalt pavements: A practical guide to design, production and maintenance for engineers and architects. CRC Press.

[29] Moghaddam, T. B., Soltani, M., \& Karim, M. R. (2014). Experimental characterization of rutting performance of polyethylene terephthalate modified asphalt mixtures under static and dynamic loads. Construction and Building Materials, 65, 487-494. https://doi.org/10.1016/j.conbuildmat.2014.05.006

[30] Naseri, F., Jafari, F., Mohseni, E., Tang, W., Feizbakhsh, A., \& Khatibinia, M. (2017). Experimental observations and SVM-based prediction of properties of polypropylene fibres reinforced self-compacting composites incorporating nano$\mathrm{CuO}$. Construction and Building Materials, 143, 589-598. https://doi.org/10.1016/j.conbuildmat.2017.03.124

[31] Badarloo, B. \& Jafari, F. (2018). A Numerical Study on the Effect of Position and Number of Openings on the 
Performance of Composite Steel Shear Walls. Buildings, 8(9), 121. https://doi.org/10.3390/buildings8090121

[32] Ghanei, A., Jafari, F., Khotbehsara, M. M., Mohseni, E., Tang, W., \& Cui, H. (2017). Effect of nano-CuO on engineering and microstructure properties of fibre-reinforced mortars incorporating metakaolin: experimental and numerical studies. Materials, 10(10), 1215.

https://doi.org/10.3390/ma10101215

\section{Contact information:}

Mahmoud AMERI, Professor,

Iran University of Science and Technology,

University St., Hengam St., Resalat Square, Tehran, Iran

E-mail: amerii@iust.ac.ir

Hamid SHAKER, PHD student,

(Corresponding author)

Iran University of Science and Technology,

University St., Hengam St., Resalat Square, Tehran, Iran

E-mail: h_shaker@civileng.iust.ac.ir

\section{Baitollah BADARLO0,}

Department of Civil Engineering

Qom University of Technology (QUT),

Qom, Iran

\section{Faezeh JAFARI}

Department of Civil Engineering,

Malayer University,

Malayer 65719-95863, Iran 